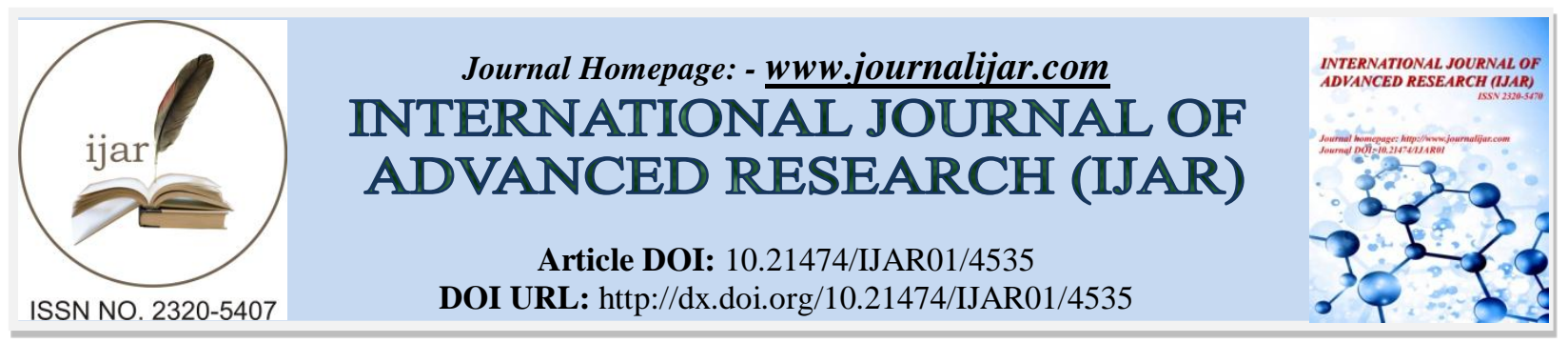

RESEARCH ARTICLE

\title{
ANATOMICAL AND PHYSIOLOGICAL CONSIDERARTIONS IN MANAGEMENT OF ODONTOGENIC CELLULITIS IN A FIVE YEAR OLD PATIENT: REPORT OF A CASE.
}

Dr Kanupriya Rathore.

Senior lecturer, Jodhpur Dental College and General Hospital, Jodhpur.

\section{Manuscript Info}

Manuscript History

Received: 19 April 2017

Final Accepted: 21 May 2017

Published: June 2017

Key words:-

Facial cellulitis, Caries, odontogenic infection

\section{Abstract}

Odontogenic facial cellulitis refers to infections arising from the dentition and its adjacent supporting periodontal structure. Facial involvement has higher risk of complications due to the proximity of sensitive anatomical structures. Cellulitis is mainly caused by Staphylococcus aureus and Streptococcus pyogenes (especially Group A beta-haemolytic S. pyogenes). Patients present with local symptoms such as erythema, swelling, tenderness and warmth and may also have systemic symptoms. Pediatric patients deserve special considerations with respect to anatomic, physiologic and pharmacologic differences from adults. Early diagnosis and correct treatment with broad-spectrum antibiotics is mandatory to avoid life-threatening complications.

Copy Right, IJAR, 2017,. All rights reserved.

\section{Introduction:-}

Cellulitis is a diffuse inflammation of soft tissues which is not circumscribed or confined to one area and tends to spread through tissue spaces and along the facial planes (Ginsberg, 1981). One of the most common causes of acute infection of the oral cavity is untreated dental caries. Early diagnosis and management of orofacial infections in children is crucial to prevent systemic involvement (Cachovan et al., 2013). In children, unlike adults, the location of various anatomic infections is thought to be a helpful guide for diagnosis and management (Flynn, 2003).

Early diagnosis and treatment of pediatric facial cellulitis are challenging because of its variable clinical presentations, including multiple potential sources of infection and multiple organisms within the head and neck area hence Rapid and thorough initial assessment is the key to successful management (Biederman and Dodson, 1994; Dodson et al., 1991).

\section{Case Report:-}

A 5 year old boy presented with a 2 day history of severe pain and swelling in lower left side of face (Fig. 1). Patient gave history of swelling and pain on left lower back region of face. Mild pain was present since 7-10 days. The swelling was accompanied by local erythema and tenderness. His parents stated that he has decreased appetite and activity since 2 days and there was no history of trauma or recent insect bite on the face. No medicines and treatment were taken for the same.

Extra oral examination revealed a diffuse, indurated and non fluctuant swelling in left side of face extending superiorly from infraorbital region to lower border of mandible, anteriorly from angle of mouth to ala tragus line (Fig. 1). Submandibular and submental lymphnodes were tender on palpation. Intraorally the mandibular left 
vestibule was obliterated. Patient had limited mouth opening. As the clinical and radiographic findings were consistent, hence the patient was diagnosed with facial cellulitis secondary to infection associated with carious lower left primary second mandibular molar. Intraoral examination (Fig. 2 A,B,C) revealed multiple carious teeth (Deep caries in 54,55,64,65,74,75; Moderate arrested caries 85; Moderate caries 51,52,61,62,63,84).

Local treatment was imposed which included emergency access opening to the infected tooth and debridement in order to decompress the affected area. Saline and sodium hypochlorite irrigation was done, open formocresol dressing was given and patient was recalled the next day for further treatment. The patient remained on an oral dose of antibiotics for 5 days. The post operative period was uneventful. Resolution of cellulitis was confirmed after 5 days.

Other treatment included oral prophylaxis and oral hygiene instructions, composite build up was done in $51,52,61,62$; pulpectomy in 75 , pulpotomy in 54,55,64,65.74; stainless steel crowns were given in 54,55,64,64,74,75,85 ( Fig. 3 A,B,C).

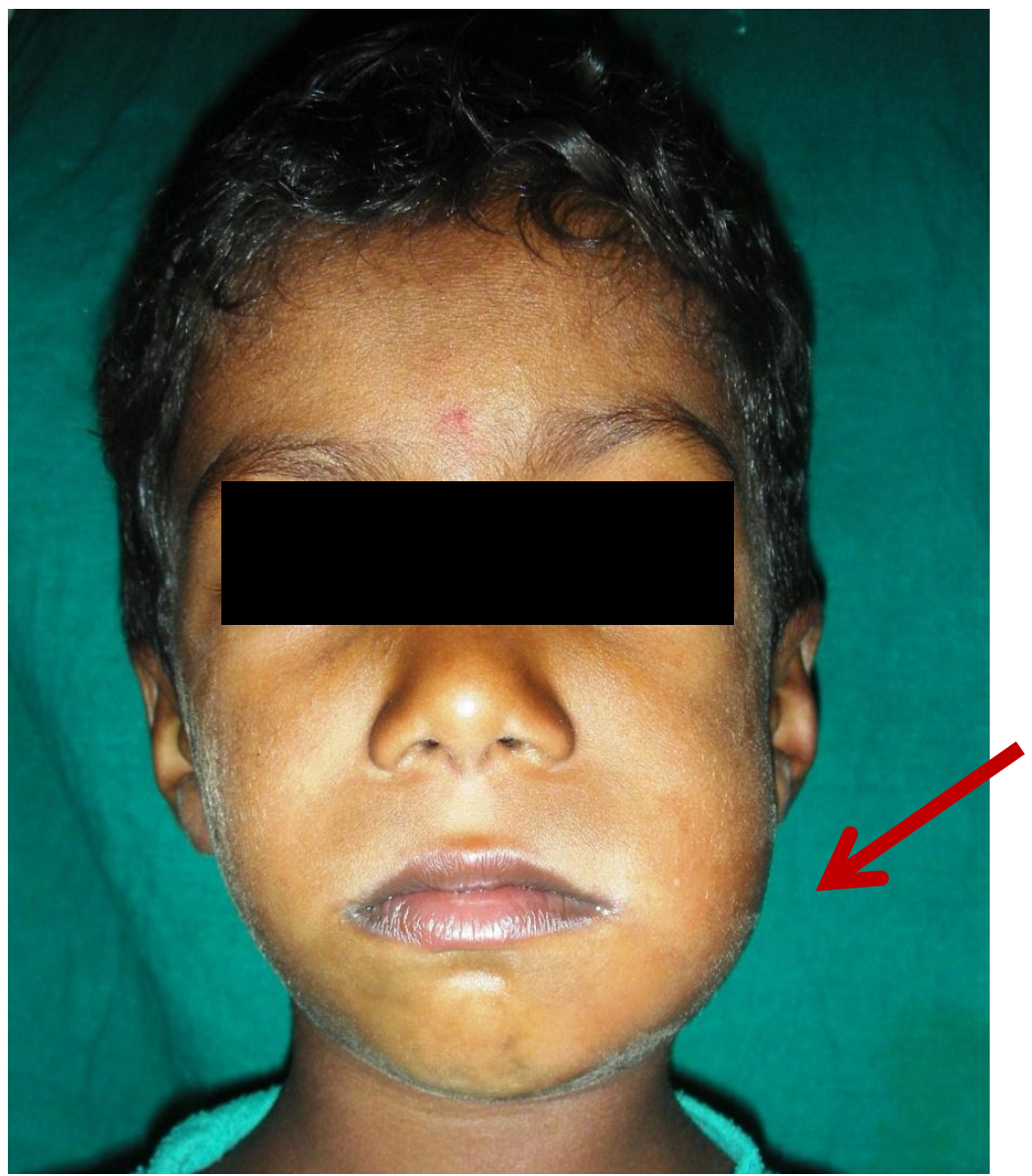

Fig. 1:-
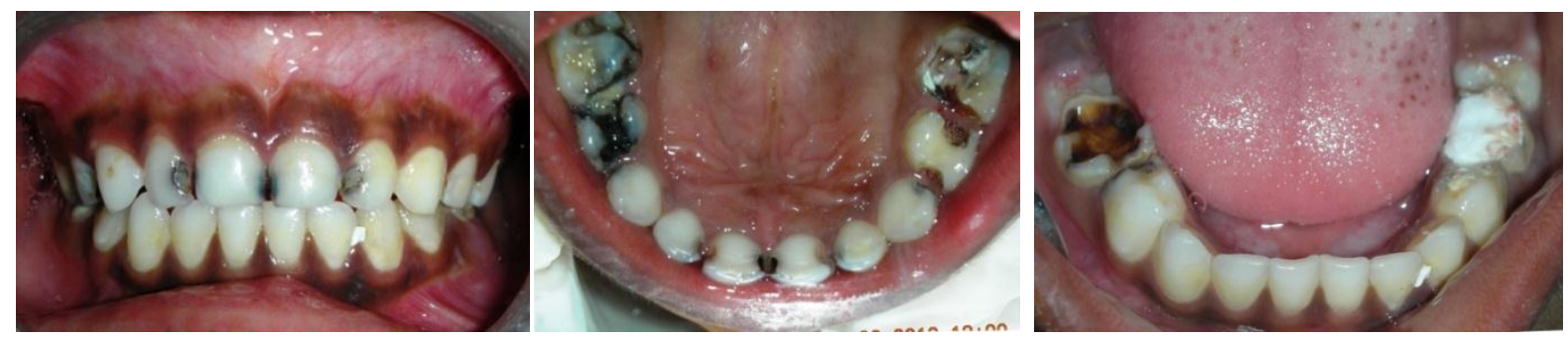

Fig. 2:- A,B,C 

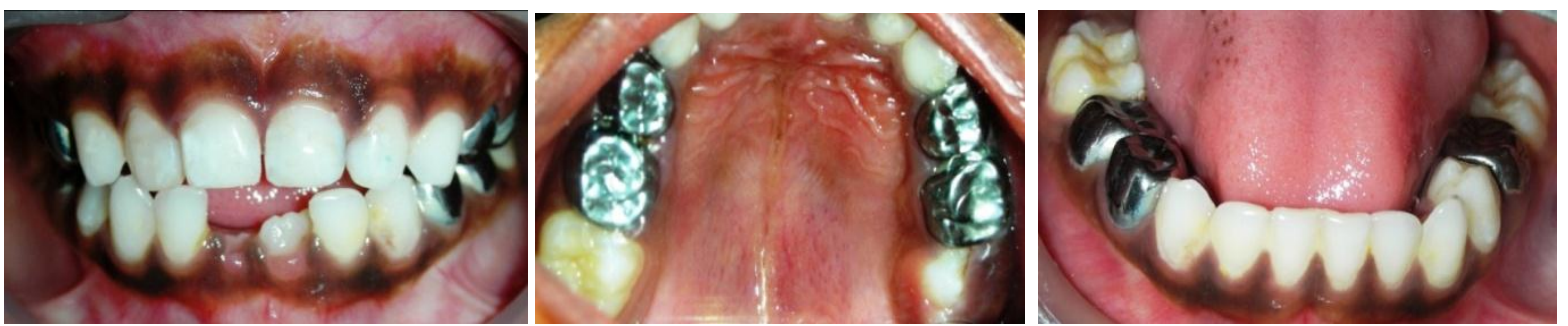

Fig. 3:- A,B,C:

\section{Discussion:-}

Most orofacial infections are considered to be odontogenic in origin, whereas others are self-limiting in nature (Heimdahl et al., 1985). Many of these cases result from neglected dental caries; these infections can progress to facial cellulitis and systemic toxicity if untreated (Sandor et al., 1998a) Odontogenic infections are polymicrobial, with anaerobic and mixed aerobic bacteria (Dodson et al., 1989). In pediatric facial infections, disease can progress quickly, producing significant systemic symptoms, including fever, dehydration, and airway obstruction (Sandor et al., 1998a), because of the possibility of progression to systemic disease, early management and recognition of orofacial infections in children is necessary (Dodson et al., 1989).

Moreover, management of these infections in pediatric patients is critical as they have the tendency to become dehydrated and systemically ill very rapidly as a result of refusal to take fluids because of oral pain (Schuman and Owens, 1992). The clinical manifestations of orofacial infections are largely dictated by complex microflora and anatomic routes of spread of infection (Granite, 1976; Brook, 1981). Therefore pediatric dentist must have a proper knowledge of the etiology and overall management of these young patients as he/she is the first health profession to see children with facial swelling, pain and fever.

\section{Clinical significance:-}

In children, unlike adults, the location of various anatomic infections is thought to be a helpful guide for diagnosis and management (Flynn et al.; 2003). Infections spread rapidly in the jaws of a child because of the wide marrow spaces and also because of lesser density of bones in developing children than adult bones (Granite, 1976). For this reason, prompt treatment should be given to children in a short time. The pediatric dentist must pay attention to alarm signs which may lead to hospitalization.

Another primary difference between adults and children as far as the spread of infection is concerned is the relationship of the apices of teeth to the attachment of facial muscles on the maxilla and mandible (Granite, 1976). Compared to adults, children have a relatively short facial height so the apices of teeth, especially the permanent first molars, incisors and canines are found to be outside the limits of the attachment of the facial muscles. In the mandible, molar infections tend to spread into the submandibular spaces (Biederman and Dodson, 1994: Granite, 1976). Infections from the anterior teeth may spread into the submental space or into the fibers of the mentalis muscle, causing very painful cellulitis. In the maxilla, infections that break out above its attachment tend to dissect medially to the nasolabial fold region (Granite, 1976).

An intraosseous infection can also cause complete destruction of the permanent tooth germs and if undiagnosed may reach the critical growth centers of jaws like the condyle. The condylar region of the mandible is the most sensitive area that can be grossly disfigured if its growth is disturbed. Moreover, abscess formation and cellulitis are quite exaggerated in children and if correct treatment is not rendered, severe consequences like cavernous sinus thrombosis, blindness, brain abscess, septicemia and airway obstruction can occur (Granite, 1976). In children, detection of the primary etiologic site and microorganisms responsible for the orofacial infection is very difficult, because of the close proximity of the skin, teeth, salivary glands, sinuses, and eustachian tubes (Granite EL, 1976).

General anatomical and physiological characteristics of children are varied because the age range covered by Pediatric Dentistry is wide. For instance, the percent of body water and fat, as well as liver enzymes and plasma proteins levels, are different in neonates and infants from those of children and adolescents. Therefore, body size and composition, immature gastrointestinal, renal and immune system and nutritional status should be considered when assessing odontopediatric patients (Pinkham, 1999). Adequate dose adjustment of medication is required in 
children, as greater proportion of water in the tissues of children and their increased bone sponginess facilitate faster diffusion of infection. (Paloma et al., 2006)

\section{Conclusion:-}

Odontogenic Cellulitis in children is a dental emergency that must be handled at an infant stage. People at any age can be affected, although infants and the elderly are at higher risk. Children particularly are susceptible to rapid systemic involvement therefore early diagnosis and management of an emergent facial swelling is critical for a successful resolution.

Complications are a rare possibility but can turn life-threatening if the treatment is delayed. Treatment for specific types of cellulitis may be given; following microbiological findings based on cultures and drug sensitivities. Most patients recover completely after timely antibiotics.

\section{References:-}

1. Biederman, GR. and Dodson, TB. (1994): Epidemiologic review of facial infections in hospitalized pediatric patients. J Oral Maxillofac Surg., 52(10):1042-1045.

2. Brook, I., Grimm, S. and Kielich, RB., (1981): Bacteriology of acute periapical abscess in children. J Endod., 7(8):378-380.

3. Brook, I. (2003): Microbiology and management of deep facial infections and Lemierre syndrome. J. Otorhinolaryngol. Relat. Spec., 65(2):117-120.

4. Cachovan, G., Phark, J.H., Scho“ n, G., Pohlenz, P. and Platzer, U. (2013): Odontogenic infections: an 8-year epidemiologic analysis in a dental emergency outpatient care unit. Acta Odontol. Scand., 71(3-4):518-524.

5. Dodson, T.B., Perrott, D.H., Kaban, L.B. (1989): Paediatric maxillofacial infections: a retrospective study of 13 patients. J. Oral Maxillofac. Surg., 47(4):327-330.

6. Dodson, TB., Perrott, DS. and Kaban, LB. (1991): Predictors of outcome in children hospitalized with maxillofacial infections: a linear logistic model. J Oral Maxillofac Surg., 49(8):838-842.

7. Flynn, T.R. and Halpern, L.R. (2003): Antibiotic selection in head and neck infections. Oral Maxillofac. Surg. Clin. North Am., 15(1):17-38.

8. Ginsberg, MB. (1981): Cellulitis: analysis of 101 cases and review of the literature. SouthMed J., 74:530-533.

9. Granite, EL. (1976): Anatomic considerations in infections of the face and neck: review of the literature. J Oral Surg., 34(1):34-44.

10. Heimdahl, A., Von Konow, L., Satoh, T. and Nord, C.E. (1985): Clinical appearance of orofacial infections of odontogenic origin in relation to microbiological findings. J. Clin. Microbiol., 22(2):299-302.

11. Pinkham, JR. (1999): Pediatric Dentistry. 3rd ed. Mexico: Mcgraw-Hill.

12. Planells del Pozo, P., Barra-Soto, MJ. and Santa Eulalia Troisfontaines E. (2006): Antibiotic prophylaxis in pediatric odontology. An update. Med Oral Patol Oral Cir Bucal., 11(4):E352-357.

13. Sandor, G.K., Low, D.E., Judd, P.L. and Davidson, R.J. (1998a): Antimicrobial treatment options in the management of odontogenic infections. J Can Dent. Assoc., 64(7):508-514.

14. Schuman, NJ. and Owens, BM. (1992): Ludwig's angina following dental treatment of a five-year-old male patient: report of a case. J ClinPediatr Dent., 16(4):263-265. 